\title{
Comparison between household food purchase and individual food consumption in Brazil
}

\author{
Dayan Carvalho Ramos Salles de Oliveira ${ }^{1, *}$, Amanda de Moura Souza ${ }^{2}$, \\ Renata Bertazzi Levy ${ }^{3}$, Rosely Sichieri ${ }^{1}$ and Eliseu Verly-J ${ }^{1}$ \\ ${ }^{1}$ Institute of Social Medicine, Rio de Janeiro State University (UER), São Francisco Xavier 524 - UERJ, Rio de Janeiro, \\ RJ 20550-013, Brazil: ${ }^{2}$ Institute of Studies in Collective Health, Federal University of Rio de Janeiro (UFRJ), Rio de \\ Janeiro, RJ, Brazil: ${ }^{3}$ Faculty of Medicine, University of São Paulo (USP), São Paulo, SP, Brazil
}

Submitted 25 January 2018: Final revision received 9 September 2018: Accepted 1 0ctober 2018: First published online 7 December 2018

\begin{abstract}
Objective: The present study aimed to compare Household Budget Survey (HBS) data on food purchasing and individual food consumption, collected in the same nationwide survey.

Design: Food purchase information for each household was collected by a sevenday collective acquisition diary, applied to 55970 households. Food consumption information was obtained from household members over 10 years old by the application of two non-consecutive food records in a sub-sample of the HBS. Cooking and correction factors were applied when necessary, and all food items reported were grouped into twelve main food groups. Food purchase and consumption data were presented as absolute weight ( $\mathrm{g} /$ person per $\mathrm{d}$ ) and as relative contribution to energy intake (\%) for the overall study population, which was stratified according to household income.

Setting: Brazil.

Participants: National estimates of food consumption and purchase for Brazil.

Results: The greatest differences between purchase and consumption data (purchase minus consumption) were observed for meat $(-168 \mathrm{~g})$, beans/legumes $(-48 \mathrm{~g})$, roots/tubers $(-36 \mathrm{~g})$ and fruits $(-31 \mathrm{~g})$. When expressed in terms of energy contribution, the highest differences were found for cereals (13\%) and oils and fats $(11 \%)$. Differences between purchase and consumption data were generally lower in the highest compared with the lowest household income quintile; and were lower for most main food groups when considering only foods reported as being eaten at home.

Conclusions: With few exceptions, food purchase expressed as relative energy contribution, as opposed to absolute weight, can provide a good picture of actual consumption in the Brazilian population.
\end{abstract}

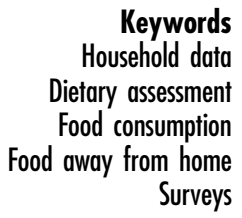

Monitoring the food consumption status of a population is fundamental in evaluating its effects on health and in supporting public health policy decisions ${ }^{(1)}$. Nationwide dietary surveys directly measure individual food consumption with appropriate collection instruments such as $24 \mathrm{~h}$ recalls or food records ${ }^{(2)}$. However, these methods are complex and expensive, which constitutes a barrier to application in middle- and low-income countries ${ }^{(3,4)}$. In the absence of such surveys, researchers have relied on food purchase data to infer data on food consumption. Household Budget Surveys (HBS) have been conducted periodically in various countries and usually collect information on the amount and price of all items purchased by household members throughout a defined period.
In Brazil, a range of publications have used information from previous HBS to describe the nutritional transition, trends in healthy and unhealthy eating, and how these occur according to socio-economic status ${ }^{(5-8)}$. Likewise, countries such as Canada ${ }^{(9)}$, Portugal ${ }^{(10)}$, Bolivia ${ }^{(11)}$, Costa Rica $^{(12)}$, Croatia $^{(13)}$ and Mexico ${ }^{(14)}$ have made use of HBS to describe dietary trends. However, the degree to which food purchase information is able to provide accurate information about what is actually eaten in a given population is a matter of debate. Discrepancies between consumption and purchase data are to be expected, given that the latter refers to the total amount acquired by a household but not necessarily eaten. For instance, purchased food can be wasted or destined for animal feeding 
and donation; besides this, some items are used as ingredients in recipes (such as wheat flour, sugar, milk, etc. $)^{(3,15,16)}$. Additionally, HBS do not collect information on foods purchased and consumed outside the home, which is considered an important source of discrepancy. Data from Brazil for 2008-2009 found that 18\% of total energy intake comes from foods eaten away from home, where the highest contributors were alcoholic beverages (of which 59\% were consumed away from home), baked and deep-fried snacks (54\%), pizza (42\%), soft drinks (40\%) and sandwiches $(40 \%)^{(17)}$.

Regarding energy intake, the concordance between purchase and consumption data varies. Purchased energy was found to be lower than consumed energy in Armenia ${ }^{(18)}$ and Cape Verde ${ }^{(19)}$; in both studies, the difference between purchased and consumed energy was found to be modified by household income. On the other hand, the opposite result was found in Kenya, in which purchased energy was found to overestimate consumption ${ }^{(20)}$. The last Brazilian HBS (2008/2009) included, for the first time, a dietary survey (National Dietary Survey (NDS)) in which a representative sub-sample self-filled two nonconsecutive food records, making it possible to compare the two methods. Louzada et al. ${ }^{(21)}$ compared estimates of ultra-processed food (UPF) products obtained from the HBS and NDS of 2008/2009 and found good agreement between them, although the purchased energy of UPF products overestimated consumption in the highest tertile of household income. However, there is no information available on how these two methods compare regarding main food groups - information which would be useful to better interpret previous studies and to support methodological decisions for future studies based on purchase data. Therefore the objective of the present study was to compare household purchase and individual food consumption data collected in two nationwide surveys, for the same households and spanning the same period.

\section{Method}

\section{Study population}

The HBS and NDS were carried out from May 2008 to May 2009 in a representative probabilistic sample of Brazilian households. The detailed sampling procedure employed in these surveys is described elsewhere ${ }^{(22)}$. Briefly, the HBS involved two-stage cluster sampling, with primary sampling units consisting of 12800 census tracts grouped into 550 sampling strata with geographical and socioeconomic homogeneity; and secondary sampling units consisting of 55970 private permanent households. Census tracts were selected through systematic sampling with probability proportional to the number of households in each stratum, and households were chosen by a simple random selection without replacement in each census tract. The information collection for each stratum was uniformly distributed throughout the 12 months of data collection. Food purchase across seven consecutive days was recorded in self-filled reports by household members, using a collective inventory booklet, which provided detailed information on quantities and prices.

NDS 2008 was conducted in a representative sample (25\%) of the HBS 2008/2009 households, consisting of 13569 households and 34003 individuals aged 10 years or older. In both surveys, the household data collection of each stratum was distributed throughout 12 months, thus accommodating seasonal effects on food purchase and consumption. Food consumption was also self-filled by all household members aged 10 years or older using food records referring to two non-consecutive days within the same week in which food purchase was recorded. Individuals provided detailed information on portions, cooking methods, additions, and time and place of consumption.

\section{Data collection}

Food purchase information for each household was collected using a seven-day collective acquisition diary, which provided detailed descriptions of the product, amount purchased, measuring units, place of purchase and the price, in both monetary and non-monetary acquisition, of foods, beverages and non-food items.

Food consumption information was obtained by the application of two non-consecutive food records, which were self-filled with detailed information including portion size, cooking method and place of consumption (at home, or not). Sugar consumption was estimated by the NDS as being $10 \%$ of the total volume of reported drinks (such as juice, tea and coffee) when the interviewee reported a preference for adding sugar, and as 5\% when they reported use of sugar and artificial sweeteners. When a participant was unable to record his/her consumption, another household member assisted in the completion of the record.

Foods reported in both the HBS and NDS surveys were grouped according to those of previous Brazilian HBS publications on food purchase ${ }^{(6,7)}$. The main groups were: cereals; beans and legumes; roots and tubers; fruits; vegetables; meat; dairy products; eggs; oils and fats; sweets; soft drinks; and alcoholic beverages.

\section{Food variables}

Mixed foods reported in both surveys were disaggregated into their ingredients based on standard recipes ${ }^{(23)}$. Most foods reported in the HBS were uncooked, meaning that their volume represented the amount as purchased (e.g. raw meat, cereals, etc.). However, the NDS collected information on foods as consumed, meaning their volume could have increased or decreased (by either water absorption or loss) so that the amount consumed could not be directly compared with the amount purchased. 
Thus, foods reported on the NDS were converted back to their 'crude' weights by correcting for cooking factors, which accounts for cooking methods such as frying and boiling $^{(24)}$. Furthermore, inedible portions of foods reported in the HBS were removed using correction factors $^{(25)}$. After suitable correction, foods were converted into energy using the appropriate nutritional composition table ${ }^{(25,26)}$. We expressed food purchase and consumption in terms of average absolute weight ( $\mathrm{g} /$ person per $\mathrm{d}$ ) and relative contribution to total energy (\%), for each food group.

\section{Data analysis}

Since the HBS covered only a $7 \mathrm{~d}$ period of purchase information, the mean purchase for an individual household is affected by the random measurement error: while some households may have bought some food items in bulk (to be used in a month, for example), others may have not bought in the week that the interview took place. To overcome this, the sampling strata were used as the unit of analysis. Daily per capita food purchase and consumption were estimated by summing the amount of foods or food groups reported and dividing this by the total number of individuals within each sampling stratum. The overall mean was calculated as the average of all 550 strata mean for each food group. Standard errors and $95 \%$ confidence intervals were calculated considering sampling weights and the complex sampling design of the surveys. Results are presented for the overall population and stratified into quintiles of household income. Given the fact that the HBS records food purchases that are potentially consumed at home by all household members, and that the NDS records foods consumed by individuals aged 10 years or older including those consumed away from home, two additional comparisons were performed: (i) considering only those foods reported in the NDS as being consumed at home; and (ii) considering only those households with individuals aged 10 years or older in the HBS.

\section{Results}

Table 1 shows the results comparing purchase and consumption data, as expressed in terms of relative contribution to total energy. There were no significant differences between the two methods for cheese, eggs, fruits, soft drinks and alcoholic beverages. Mean purchase was found to be higher for cereals, vegetables, sweets and dairy products; while it was lower for beans/legumes, roots/tubers and meats. Table 2 presents the results comparing purchase and consumption data expressed in terms of absolute weight. The mean of purchased goods was statistically lower than the mean of consumption for most foods, except for rice and sweets. No differences were found between the two methods for soft drinks, vegetables or cereals (Table 2).

The greatest differences between the methods were observed for meat (168g/person per d), beans/legumes

Table 1 Mean purchase and consumption of foods, in terms of relative contribution to total energy (\%), estimated from the Household Budget Survey (HBS) and National Dietary Survey (NDS), Brazil, 2008/2009

\begin{tabular}{|c|c|c|c|c|}
\hline \multirow[b]{2}{*}{ Food group } & \multicolumn{2}{|c|}{ HBS } & \multicolumn{2}{|c|}{ NDS } \\
\hline & Mean & $95 \% \mathrm{Cl}$ & Mean & $95 \% \mathrm{Cl}$ \\
\hline Cereals & 35.45 & $34 \cdot 77,36 \cdot 13$ & $22.44^{*}$ & $22.08,22 \cdot 80$ \\
\hline Rice & $15 \cdot 80$ & $15 \cdot 10,16 \cdot 50$ & $9 \cdot 23^{*}$ & $8 \cdot 85,9.61$ \\
\hline Breads & 8.98 & $8.45,9.51$ & $8 \cdot 11^{*}$ & $7.82,8.40$ \\
\hline Pasta & $2 \cdot 82$ & $2 \cdot 71,2.93$ & $2 \cdot 53^{*}$ & $2 \cdot 37,2.69$ \\
\hline Beans and legumes & $5 \cdot 23$ & $4.93,5.52$ & $10 \cdot 06^{*}$ & $9.66,10.46$ \\
\hline Roots and tubers & 1.17 & $1.11,1.23$ & $1 \cdot 71^{*}$ & $1.58,1.84$ \\
\hline Fruits & $2 \cdot 17$ & $2 \cdot 06,2.29$ & $2 \cdot 23$ & $2 \cdot 10,2 \cdot 35$ \\
\hline Vegetables & 0.64 & $0.61,0.66$ & $0.38^{*}$ & $0.35,0.41$ \\
\hline Meats & $13 \cdot 34$ & $12 \cdot 96,13.72$ & $16 \cdot 77^{\star}$ & $16 \cdot 13,17 \cdot 40$ \\
\hline Red meat & 5.64 & $5.46,5.82$ & $9 \cdot 47^{\star}$ & $9 \cdot 12,9.82$ \\
\hline Chicken & 4.22 & $4.04,4.40$ & $5 \cdot 55^{\star}$ & $4 \cdot 99,6 \cdot 12$ \\
\hline Fish & 0.61 & $0.54,0.69$ & $1.66^{*}$ & $1.38,1.94$ \\
\hline Processed meat & 0.01 & $0.00,0.01$ & $0 \cdot 17^{*}$ & $0 \cdot 15,0.19$ \\
\hline Dairy products & 6.33 & $6 \cdot 08,6.58$ & $4 \cdot 23^{*}$ & $4.05,4.40$ \\
\hline Milk & 4.51 & $4.31,4.71$ & $2 \cdot 16^{*}$ & $2 \cdot 07,2 \cdot 24$ \\
\hline Cheese & 1.04 & $0.96,1.13$ & 1.01 & $0.91,1.10$ \\
\hline Eggs & 0.72 & $0.69,0.75$ & 0.80 & $0.75,0.86$ \\
\hline Oils and fats & $13 \cdot 31$ & $12.93,13.70$ & $1 \cdot 77^{\star}$ & $1.68,1.86$ \\
\hline Vegetable oils & $10 \cdot 79$ & $10 \cdot 39,11 \cdot 20$ & $0.01^{*}$ & $0.01,0.02$ \\
\hline Butter & 0.36 & $0.31,0.40$ & $0.74^{*}$ & $0.68,0.80$ \\
\hline Sweets & $13 \cdot 36$ & $13 \cdot 01,13 \cdot 72$ & 2.67 & $2 \cdot 51,2.90$ \\
\hline Sugar & $10 \cdot 87$ & $10.45,11.28$ & $0.04^{*}$ & $0.02,0.05$ \\
\hline Soft drinks & 1.57 & $1.47,1.67$ & 1.44 & $1.34,1.53$ \\
\hline Alcoholic beverages & 0.68 & $0.60,0.77$ & 0.79 & $0.66,0.92$ \\
\hline
\end{tabular}

*Mean food values were significantly different between surveys $(P<0.05)$. 
Table 2 Mean purchase and consumption of foods, in terms of absolute amount (g/person per $\mathrm{d}$ ), estimated from the Household Budget Survey (HBS) and National Dietary Survey (NDS), Brazil, 2008/2009

\begin{tabular}{|c|c|c|c|c|}
\hline \multirow[b]{2}{*}{ Food group } & \multicolumn{2}{|c|}{ HBS } & \multicolumn{2}{|c|}{ NDS } \\
\hline & Mean & $95 \% \mathrm{Cl}$ & Mean & $95 \% \mathrm{Cl}$ \\
\hline Cereals & 170.52 & $163.67,177.38$ & 161.48 & $158.51,164.44$ \\
\hline Rice & 72.69 & $67.99,77.39$ & $62 \cdot 10^{*}$ & $59.78,64.42$ \\
\hline Breads & 44.75 & $42 \cdot 80,46 \cdot 71$ & $64.79^{\star}$ & $62 \cdot 25,67 \cdot 33$ \\
\hline Pasta & $12 \cdot 29$ & $11.62,12.96$ & $16 \cdot 60^{*}$ & $15.44,17.77$ \\
\hline Beans and legumes & 25.89 & $23 \cdot 95,27 \cdot 84$ & $73 \cdot 84^{*}$ & $70.73,76.95$ \\
\hline Roots and tubers & 24.76 & $23 \cdot 27,26 \cdot 24$ & $60 \cdot 92^{*}$ & $57 \cdot 14,64 \cdot 69$ \\
\hline Fruits & 57.97 & $54.34,61.60$ & $89.34^{*}$ & $84.25,94.43$ \\
\hline Vegetables & 39.36 & $37 \cdot 30,41 \cdot 41$ & 40.03 & $37 \cdot 30,42 \cdot 77$ \\
\hline Meats & $105 \cdot 77$ & $101 \cdot 76,109 \cdot 78$ & $273.96^{*}$ & $260.57,287.34$ \\
\hline Red meat & $45 \cdot 32$ & $43.34,47 \cdot 30$ & $187 \cdot 28^{*}$ & $180 \cdot 12,194.44$ \\
\hline Chicken & $33 \cdot 16$ & $31.82,34.49$ & $84 \cdot 27^{\star}$ & $73 \cdot 28,95 \cdot 26$ \\
\hline Fish & 8.40 & $7.08,9.72$ & $34.45^{\star}$ & $27 \cdot 67,41 \cdot 23$ \\
\hline Processed meat & 0.07 & $0.03,0.11$ & $2 \cdot 13^{*}$ & $1.86,2.39$ \\
\hline Dairy products & 118.65 & $112.08,125.22$ & $132 \cdot 20^{*}$ & $126.63,137.77$ \\
\hline Milk & 103.59 & $97.51,109.66$ & $116 \cdot 37^{*}$ & $111.80,120.95$ \\
\hline Cheese & $5 \cdot 60$ & $5 \cdot 10,6 \cdot 11$ & $7 \cdot 90^{*}$ & $7 \cdot 12,8.67$ \\
\hline Eggs & 8.08 & $7.72,8.45$ & $13 \cdot 22^{*}$ & $12 \cdot 31,14 \cdot 14$ \\
\hline Oils and fats & $26 \cdot 63$ & $25 \cdot 42,27 \cdot 84$ & $6 \cdot 60^{*}$ & $6 \cdot 20,6 \cdot 99$ \\
\hline Vegetable oils & 19.66 & $18.58,20 \cdot 73$ & $0.03^{*}$ & $0.02,0.04$ \\
\hline Butter & 0.75 & $0.66,0.85$ & $2 \cdot 37^{*}$ & $2 \cdot 15,2.59$ \\
\hline Sweets & 59.06 & $56.48,61.64$ & $33.87^{*}$ & $30.91,37.26$ \\
\hline Sugar & $46 \cdot 22$ & $43 \cdot 74,48 \cdot 70$ & $0.22^{*}$ & $0.15,0.29$ \\
\hline Soft drinks & 105.98 & $97.92,114.05$ & $98 \cdot 23$ & $91.08,105.38$ \\
\hline Alcoholic beverages & $19 \cdot 24$ & $16 \cdot 82,21.66$ & $31.22^{*}$ & $26.56,35.88$ \\
\hline
\end{tabular}

${ }^{*}$ Mean food values were significantly different between surveys $(P<0.05)$.

( $48 \mathrm{~g} /$ person per $\mathrm{d})$, roots/tubers $(36 \mathrm{~g} /$ person per $\mathrm{d})$ and fruits $(31 \mathrm{~g} /$ person per d) when expressed as absolute amounts (Fig. 1(a)). When expressed as an energy contribution, the greatest differences were found for cereals (12\% difference) and oils and fats (11\%; Fig. 1(b)). Figure 1 also shows the differences between the two methods when restricting the analysis to foods reported as eaten in the home in the nutritional survey. The differences between the methods tended to be smaller for most of the main food groups (except for soft drinks and cereals), especially when the results were expressed as energy contribution (Fig. 1(c) and (d)). Differences between purchase and consumption data were, in most cases, lower in the highest compared with the lowest household income quintiles (Fig. 1(g) and (h)).

When comparing only foods eaten at home as recorded in the NDS with foods purchased as recorded in the HBS, the differences between them, in absolute amounts, were smaller for some items compared with the whole sample, particularly for meats, dairy products, fruits and alcoholic beverages; with increased difference mainly found for cereals and soft drinks (Fig. 1(c)). On the other hand, when expressed as an energy contribution, differences were comparable across the whole sample, except for cereals (Fig. 1(d)).

These similarities and differences between the two methods were also observed to be of the same magnitude when considering only those households with individuals aged 10 years or older in the HBS (Fig. 1(e) and (f)).

\section{Discussion}

In the present study, we compared means of foods purchased and consumed from a large nationwide survey. In general, purchase information underestimated food consumption in terms of absolute weight for most items; but when both purchase and consumption data were expressed in terms of relative contribution to total energy, differences between the methods tended to be small. For example, the difference between purchase and consumption data for meats and roots/tubers was 168 and $36 \mathrm{~g} /$ person per $\mathrm{d}$, respectively, implying an important discrepancy between the methods. These differences were considerably smaller in terms of energy contribution (3.30 and $0.53 \%$, respectively). The implications of these results are of special importance for Brazil, given that information on nutrition transition and trends in food consumption are derived from purchase data ${ }^{(5-8)}$. Concern about how much one can infer on consumption from purchase data has increased among researchers considering the high participation of foods away from home (15\%). Thus, despite disagreement regarding some items, Brazilian food trends over the last four decades are possibly well described from purchase data. For some food items, such as cereals, meat and beans/legumes, however, the inference on consumption from household availability seems to be limited.

Discrepancies between purchase and consumption data are to be expected since the purpose, and instruments, of data collection differ. However, some of the discrepancies 
(a)

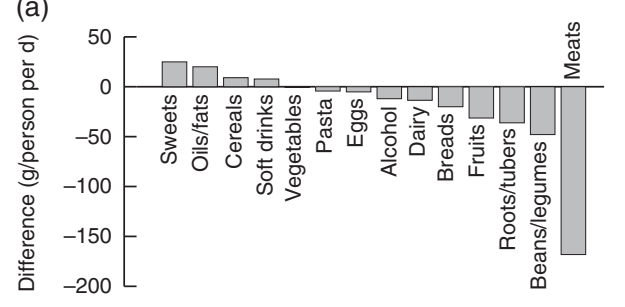

(c)

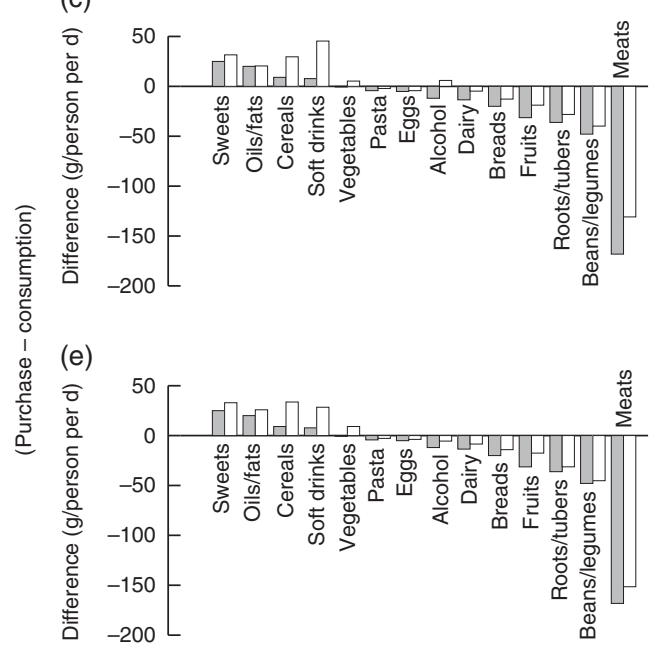

(g)

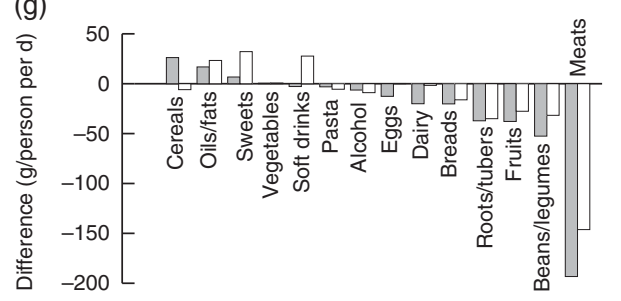

(b)

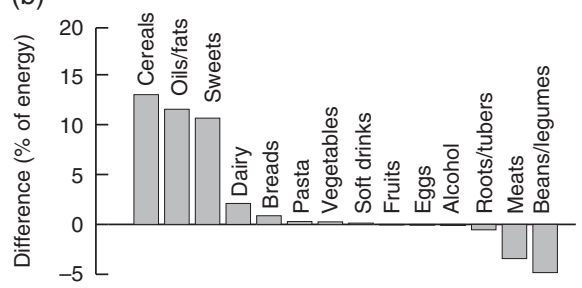

(d)

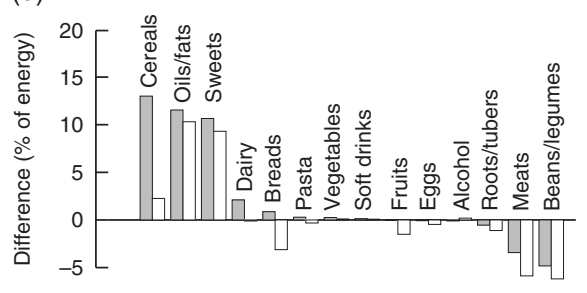

(f)

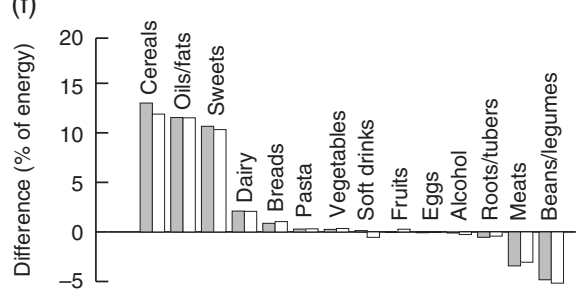

(h)

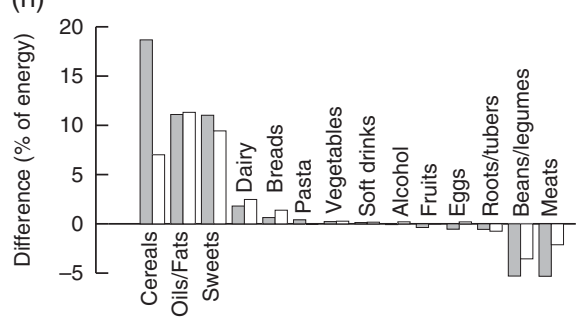

Fig. 1 Differences between mean purchase and consumption of foods, in terms of absolute amount ( $\mathrm{g} /$ person per d; left column) and relative contribution to total energy (\%; right column), by main food group. Differences calculated as (purchase - consumption): (a, b) all households; (c, d) considering foods reported as eaten in the home ( $\square$, all households; $\square$, all households but counting only those foods reported to be eaten inside the home in the NDS); (e, f) considering age of household members ( $\square$, all households; $\square$, households with members aged 10 years or older in the HBS); (g, h) considering household income ( $\square$, lowest income quintile; $\square$, highest income quintile). Data from the Household Budget Survey (HBS) and National Dietary Survey (NDS), Brazil, 2008/2009

might be better explained by how the foods are used at home. For example, water absorption during the cooking process makes cooked beans heavier than raw beans. However, even after making corrections for cooking factors, which removes the weight gained through cooking, the differences between methods are still important. In this specific case, there may have been an overestimation of the beans consumed since they are often eaten as 'bean broth' in Brazil, which adds extra water increasing the weight and volume. On the other hand, vegetable oils and sugar are often used as ingredients in recipes (such as cookies, cakes, drinks, etc.) rather than being eaten directly, which might mean their consumption is not accurately reported with instruments such as $24 \mathrm{~h}$ recalls or food records. This would explain the large difference between the data from the two methods for oils and fats.
Another study in Brazil ${ }^{(27)}$ assessed differences between purchase and consumption data using only data from the biggest city in Brazil (São Paulo). That study found an overestimation in fruit (36\%) and vegetable (93\%) purchase compared with actual gram intake from a $24 \mathrm{~h}$ recall. This divergence from our results may be due to methodological issues: we disaggregated recipes into food ingredients and accounted for all of them in a corresponding main food group (e.g. tomatoes and carrots in a mixed dish were assigned to the vegetables group); besides, the previous study did not correct for cooking factors, which would increase the amount eaten due to water absorption during cooking. Nevertheless, some of our results are in accordance with studies from Kenya ${ }^{(20)}$ and Poland ${ }^{(28)}$, which found similar results for cereals, dairy products, pulses and sugar in terms of energy 
contribution, and in terms of absolute average amounts for fruits, sugar, and oils and fat.

As with our study, studies using data from Cape Verde $^{(19)}$ and Armenia ${ }^{(18)}$ also observed an effect of income on the relationship between purchase and consumption: means of purchase were underestimated in lower-income households and overestimated in higherincome households. However, these analyses were limited to total energy. In Brazil, Louzada et $a l^{(21)}$ found that absolute purchases of non-UPF and UPF tend to be overestimated in higher-income households. In our analyses, mean differences between the two methods were generally found to be lower for the highest quintile of household income, which implies relatively less reliable inferences regarding food consumption from food purchase data for some items in the lower income quintile. For example, rice represents 11.8 and $7.9 \%$ of total energy in the highest quintile of household income, using purchase and consumption data, respectively. In the lowest quintile, these values are 18.6 and 9.9\%, increasing the distance between purchase and consumption information.

An important limitation of food purchase data for nutritional surveillance is the absence of foods bought or attained away from home. Borlizzi et al. ${ }^{(29)}$ highlighted that received foods eaten away from home represent about $9 \%$ of total energy consumption, with a significant influence on consumption across income strata, in Brazil. In fact, away-from-home intake represents a substantial percentage of total intake for some foods, such as breads (9.1\%), pasta (15.7\%), beans (12.4\%), fruits and vegetables (16.2\%), alcoholic beverages (60.8\%) and meats $(16.7 \%)^{(30)}$. As expected, for these items we observed higher means for consumption than for purchase, given the latter considers only purchased foods acquired for domestic consumption. However, eating away from home seems not to be the main reason for the differences found between the two methods. When considering only foods eaten at home in comparison with foods purchased, the differences were only slightly smaller than when considering all foods reported (inside and outside the home), especially for results expressed as a percentage of energy intake. In line with this finding, Louzada et al. ${ }^{(21)}$ observed a significant difference in the relative contribution of UPF and non-UPF to total energy between total purchase and consumption in Brazil. However, when comparing total purchase with consumption inside the home, the relative contributions became very similar.

Another methodological issue which merits consideration is that of the study population. In the HBS, all foods were recorded and supposed to be consumed by any household member, regardless of age. In the NDS, on the other hand, only foods consumed by individuals aged 10 years or older were recorded. Children are counted as household members in defining the population in each sample stratum, but they are expected to require less or more food in comparison with adults, which potentially could under- or overestimate foods purchased compared with foods consumed. The type of foods purchased will be impacted by the presence of children; for example, households with children are likely to purchase more milk and other dairy products compared with those without. On the other hand, adults will probably acquire more rice, beans, meats and alcoholic beverages. However, the comparison considering only households with individuals over 10 years old showed similar results, suggesting a small impact of the differences between the methods.

Finally, it is important to consider that food consumption from food records is subject to under-reporting ${ }^{(31)}$. A validation study, using the same methodology as that applied in the NDS to measure food consumption, compared energy intake in eighty-three adults with energy expenditure from double-labelled water and found the rate of under-reporting of energy intake to be about $30 \%{ }^{(32)}$. This suggests that, for most foods, differences between purchase and consumption data might be still higher, although we cannot assess the degree of this for each food item.

\section{Conclusion}

In conclusion, food purchase data, when expressed as percentage contribution to total energy, can provide a good picture of actual consumption for most main food groups consumed by the Brazilian population, with the exception of cereals, which are strongly underestimated, and beans/legumes and meat, which are overestimated. On the other hand, food purchase data expressed in terms of absolute weight over- and underestimate consumption considerably for the main food groups such as meat and beans/legumes; in such cases, their use in inferences about consumption cannot be deemed accurate.

\section{Acknowledgements}

Financial support: This study was financed in part by the Coordenação de Aperfeiçoamento de Pessoal de Nível Superior - Brasil (CAPES; grant number 1701627). CAPES had no role in the design, analysis or writing of this article. Conflict of interest: None. Authorship: D.C.R.S.O. and E.V.J. conceptualized the study question, designed the research and analysed the data. A.M.S., R.B.L. and R.S. reviewed the analyses and the manuscript and provided comments. D.C.R.S.O. and E.V.J. had primary responsibility for final content. All authors reviewed and approved the final manuscript. Ethics of buman subject participation: This study was conducted according to the guidelines laid down in the Declaration of Helsinki and all procedures involving human subjects were approved by the local ethics committee. Written informed consent was obtained from all subjects. 


\section{References}

1. World Cancer Research Fund \& American Institute for Cancer Research (2007) Diet, Nutrition, Physical Activity, and Cancer: A Global Perspective.Washington, DC: AICR.

2. Neufeld LM \& Tolentino L (2012) Nutritional surveillance: developing countries. In Encyclopedia of Human Nutrition, 3rd ed., pp. 289-302 [B Caballero, L Allen and A Prentice, editors]. Oxford: Elsevier.

3. Fiedler JL, Lividini K, Bermudez OI et al. (2012) Household consumption and expenditures surveys (HCES): a primer for food and nutrition analysts. Food Nutr Bull 33, 170-184.

4. Gibson RS (2005) Reproducibility in dietary assessment. In Principles of Nutritional Assessment, 2nd ed., pp. 129-148 [RS Gibson, editor]. New York: Oxford University Press.

5. Levy RR, Claro RM, Mondini L et al. (2012) Regional and socioeconomic distribution of household food availability in Brazil, in 2008-2009. Rev Saude Publica 46, 6-15.

6. Levy-Costa RB, Sichieri R, Pontes NS et al. (2005) Disponibilidade domiciliar de alimentos no Brasil: distribuição e evolução (1974-2003). Rev Saude Publica 39, 530-540.

7. Monteiro CA, Mondini L \& Costa RBL (2000) Secular changes in dietary patterns in the metropolitan areas of Brazil (1988-1996). Rev Saude Publica 34, 251-258.

8. Mondini L \& Monteiro CA (1994) Mudanças no padrão de alimentação da população urbana brasileira (1962-1988). Rev Saude Publica 28, 433-439.

9. Moubarac JC, Batal M, Martins AP et al. (2014) Processed and ultra-processed food products: consumption trends in Canada from 1938 to 2011. Can J Diet Pract Res 75, 15-21.

10. Santos DM, Oliveira BM, Rodrigues SS et al. (2014) Effect of sociodemographic variables and time on food group contribution to total food availability in Portuguese elderly households. J Nutr Health Aging 18, 471-478.

11. Pérez-Cueto FJ, Naska A, Monterrey J et al. (2006) Monitoring food and nutrient availability in a nationally representative sample of Bolivian households. Br J Nutr 95, 555-567.

12. Blanco-Metzler A, Claro RM, Heredia-Blonval K et al. (2017) Baseline and estimated trends of sodium availability and food sources in the Costa Rican population during 20042005 and 2012-2013. Nutrients 9, 1020-1031.

13. Antonić-Degac K, Kamenski M, Butigan M et al. (2010) Using of household budget survey data for public health monitoring of dietary habits in Croatia-DAFNE initiative. Acta Med Croatica 64, 17-24.

14. Valencia-Valero RG \& Ortiz-Hernández L (2014) Food availability according to food security-insecurity among Mexican households. Salud Publica Mex 56, 154-164.

15. Murphy S, Ruel M \& Carriquiry A (2012) Should household consumption and expenditures surveys (HCES) be used for nutritional assessment and planning? Food Nutr Bull 33, 3 Suppl., S235-S241.

16. Bermudez OI, Lividini K, Smitz MF et al. (2012) Estimating micronutrient intakes from Household Consumption and Expenditures Surveys (HCES): an example from Bangladesh. Food Nutr Bull 33, 208-213.

17. Bezerra IN, Souza AM, Pereira RA et al. (2013) Contribution of foods consumed away from home to energy intake in Brazilian urban areas: the 2008-9 Nationwide Dietary Survey. Br J Nutr 109, 1276-1283.

18. Martirisova D (2008) Food data collected using acquisition and consumption approaches with daily diaries in Armenia's ILCS 2004. In Deriving Food Security Information from National Household Budget Surveys: Experiences, Achievements, Challenges, pp. 59-67 [R Sibrian, editor]. Rome: FAO; available at http://www.fao.org/3/a-i0430e.pdf
19. Pereira C, Troubat N \& Sibrian R (2008) Food data collected using acquisition and intake approaches in Cape Verde's IDRF 2001/2002. In Deriving Food Security Information from National Household Budget Surveys: Experiences, Achievements, Challenges, pp. 81-88 [R Sibrian, editor]. Rome: FAO; available at http://www.fao.org/3/a-i0430e.pdf

20. Kaara J \& Ramasawmy S (2008) Food data collected using acquisition and consumption approaches with a seven-day recall method in Kenya's KIHBS 2005/2006. In Deriving Food Security Information from National Household Budget Surveys: Experiences, Achievements, Challenges, pp. 69-78 [R Sibrian, editor]. Rome: FAO; available at http:// www.fao.org/3/a-i0430e.pdf

21. Louzada MLC, Levy RB, Martins APB et al. (2017) Validating the usage of household food acquisition surveys to assess the consumption of ultra-processed foods: evidence from Brazil. Food Policy 72, 112-120.

22. Instituto Brasileiro de Geografia e Estatística (2010) Pesquisa de Orçamentos Familiares 2008-2009: Avaliação Nutricional da Disponibilidade Domiciliar de Alimentos no Brasil. Rio de Janeiro, RJ: IBGE.

23. Pinheiro ABV, Lacerda EMA, Benzecry EH et al. (2009) Quantidade dos alimentos constituintes das preparações elaboradas. In Tabela para Avaliação de Consume Alimentar em Medidas Caseiras, 5th ed., pp. 117-126 [ABV Pinheiro, EMA Lacerda, EH Benzecry et al., editors]. Rio de Janeiro, RJ: Atheneu.

24. Bognár A (2002) Tables on Weight Yield of Food and Retention Factors of Food Constituents for the Calculation of Nutrient Composition of Cooked Foods (Dishes). Karlsruhe: Federal Research Centre for Nutrition, Institute of Chemistry and Biology.

25. Instituto Brasileiro de Geografia e Estatística (1999) Estudo Nacional da Despesa Familiar (ENDEF): Tabelas de Composição de Alimentos. Rio de Janeiro, RJ: IBGE; available at https://www.biblioteca.ibge.gov.br/visualizacao/monografias/ GEBIS\%20-\%20RJ/endef/1999_Tabela\%20de\%20composicao $\% 20 \mathrm{de} \% 20$ alimentos.pdf

26. Instituto Brasileiro de Geografia e Estatística (2011) Pesquisa de Orçamentos Familiares 2008-2009: Tabelas de Composição Nutricional dos Alimentos Consumidos no Brasil. Rio de Janeiro, RJ: IBGE.

27. Claro RM, Jaime PC, Lock K et al. (2010) Discrepancies among ecological, household, and individual data on fruits and vegetables consumption in Brazil. Cad Saude Publica 26, 2168-2176.

28. Sekula W, Nelson M, Figurska K et al. (2004) Comparison between household budget survey and 24-hour recall data in a nationally representative sample of Polish households. Public Health Nutr 8, 430-439.

29. Borlizzi A, Delgrossi ME \& Cafiero C (2017) National food security assessment through the analysis of food consumption data from Household Consumption and Expenditure Surveys: the case of Brazil's Pesquisa de Orçamentos Familiares 2008/09. Food Policy 72, 20-26.

30. Bezerra IN, Souza AM, Pereira RA et al. (2013) Consumo de alimentos fora do domicílio no Brasil. Rev Saude Publica 47, 200-211.

31. Prentice RL, Mossavar-Rahmani Y, Huang Y et al. (2011) Evaluation and comparison of food records, recalls, and frequencies for energy and protein assessment by using recovery biomarkers. Am J Epidemiol 174, 591-603.

32. Lopes TS, Luiz RR, Hoffman DJ et al. (2016) Misreport of energy intake assessed with food records and 24-h recalls compared with total energy expenditure estimated with DLW. Eur J Clin Nutr 70, 1259-1264. 